\title{
ADVERSE REACTIONS TO PROCAINAMIDE
}

\author{
D.H. LAWSON* \& H. JICK \\ Boston Collaborative Drug Surveillance Program, Boston University Medical Centre, \\ 400 Totten Pond Road, Waltham, Mass. 02154, USA
}

1 Data from a comprehensive drug surveillance programme are analysed to provide details of procainamide use and toxicity in medical wards of teaching hospitals in five countries.

2 Out of a total of 488 recipients $9.2 \%$ had one or more adverse effect attributed to the drug; common effects being arrhythmias, gastro-intestinal upsets and drug fever. Although occasionally of major severity, no patient died as a consequence of procainamide toxicity.

3 Toxicity was directly related to total daily dose and duration of hospitalization but was not related to age, weight of the patient or presenting urea or albumin concentrations.

\section{Introduction}

Procainamide is an effective anti-dysrhythmic agent with an action similar to quinidine (Biggar \& Heissenbuttel, 1969; Mason, Spann, Zelis \& Amsterdam, 1970). It has been used for many years primarily to prevent ventricular dysrhythmias in patients with recent myocardial infarction (Reynell, 1961). Because of its cardio-depressant properties procainamide has been reported to produce hypotension, arrhythmias and cardiac failure. The present study provides information on the adverse effects attributed to procainamide in $\mathbf{4 8 8}$ consecutive medical in-patients who received the drug in wards participating in the Boston Collaborative Drug Surveillance Program.

\section{Methods}

The aims and methods of the Boston Collaborative Drug Surveillance Program have been described in detail elsewhere (Jick, Miettinen, Shapiro, Lewis, Siskind \& Slone, 1970). Trained nurse monitors based on medical wards use standardized self-coding data sheets to record information on consecutive admissions to medical wards. The resulting record includes demographic and diagnostic details as well as information on all drugs prescribed for these patients. When drug treatment is prescribed details of the order include indication, dosage, frequency and reason for stopping as well as any unintended effects attributed to the drug by the prescribing physician. The present report is based on information accumulated since 1966 on 29,524 patients in eleven hospitals, of whom $488(1.7 \%)$ received procainamide during one or more admission.

\footnotetext{
* Present address: Royal Infirmary, Glasgow, Scotland.
}

\section{Results}

The mean age of the 488 procainamide recipients was 65 years and two-thirds were male. A primary discharge diagnosis of cardiovascular disease was given in $73 \%$ of recipients and of respiratory disease in a further $8 \%$. The remaining $19 \%$ of patients had a wide variety of other primary diagnoses. The most common single diagnoses were congestive cardiac failure (144 patients), acute myocardial infarction (116 patients) and arteriosclerotic heart disease (104 patients). The overall mortality in procainamide recipients was $13.1 \%$ (64 patients), however the attending physicians did not implicate the drug as a cause of death in any of these patients.

Procainamide was given to treat or prevent the occurrence of ventricular dysrhythmias in $96 \%$ of recipients. Many of the patients received other cardioactive drugs during their admission, including diuretics (64\%), cardiac glycosides (63\%), other antiarrhythmic agents (57\%), anti-anginal therapy (21\%) and hypotensive agents (6\%). The drug was usually given orally, $82 \%$ of patients receiving it solely by this route and a further $12 \%$ receiving both oral and parenteral procainamide. The remaining $6 \%$ received it only parenterally. The most common frequency of administering the drug was $4-5$ times daily $(40 \%$ of recipients). Some $32 \%$ were given it less frequently, $14 \%$ received it $6-7$ times daily and the remaining $12 \%$ received it 8 times daily (i.e. 3 hourly).

\section{Acute adverse effects of procainamide}

Acute adverse reactions were attributed to procainamide in 45 patients $(9.2 \%)$, and in seven of these the reaction was reported to be life-threatening (1.4\%) (Table 1). Details of the patients who sustained lifethreatening adverse reactions are shown in Table 2. 
None of those who developed severe bradycardia or heart block were consuming cardiac glycosides along with the procainamide at the time of the reaction.

Several factors were analysed to determine their possible relationship to the development of adverse reactions. There was a strong positive association between duration of hospitalization and procainamide toxicity, and separately between the prescribed daily dose and toxicity (Table 3). Reactions were reported more often in patients with a diagnosis of both cardiac failure and acute myocardial infarction (16.3\%) than with either diagnosis alone $(9.2 \%$ and $8.1 \%$ respectively), although this could have occurred by chance (Table 3). Adverse reactions were observed significantly more often in female recipients $(22 / 161-$ $13.7 \%)$ than in males $(23 / 327-7.0 \%)-\chi^{2}=5.78$, $P<0.05$ (Table 3 ). The excess frequency of reactions in females was noted at all dosage levels, and was not due to confounding by duration of hospitalization, primary diagnosis, weight of patient or their presenting blood urea nitrogen concentrations.

There was no relationship between adverse reactions and route of administration (Table 3 ), age, weight, presenting blood urea nitrogen or plasma albumin concentrations, or co-administration of other cardio-active drugs. No patients were noted to develop hallucinations or agranulocytosis during procainamide therapy.

\section{Long-term effects of procainamide use}

Eleven patients in this series of 29,524 suffered from systemic lupus erythematosis or had a significantly positive antinuclear factor antibody titre whilst receiving procainamide as out-patients prior to hospitalization. All had been taking the drug on a regular daily basis for periods exceeding three months,

Table 1 Acute adverse reactions to procainamide

Life-threatening reactions
Heart block
Tachyarrhythmias
Bradycardia and/or
hypotension
Total
Other reactions
Gastro-intestinal upsets
Drug fever
Bradycardia and hypotension
Tachyarrhythmias
Heart block
Eosinophilia
Urticaria
Total

$7(1.4 \%)$

19 8 5 3 1 1 1

All acute adverse reactions and five had taken it for periods exceeding one year.

No information was available from the study on the acetylator phenotype of patients receiving procainamide.

\section{Discussion}

Procainamide is a potent anti-arrhythmic agent with a narrow therapeutic range (Koch-Weser \& Klein, 1971). It acts by increasing the refractory period and reducing both the intrinsic cardiac automaticity and also the rate of propagation of the cardiac impulse. The therapeutic and toxic effects have been shown to relate reasonably closely with the plasma concentrations of the drug (Koch-Weser, 1971). From clinical and pharmacological considerations, KochWeser (1971) has advocated that procainamide should be administered in three hourly doses. However, Biggar (1972) reports satisfactory control of arrhythmias with six hourly administration, perhaps due to anti-arrhythmic effect of the major metabolite $N$ acetylprocainamide - which has a substantially longer half-time in the plasma than the parent compound (Elson, Strong, Lee \& Atkinson, 1975). In the present study three hourly administration was the exception (12\%) rather than the rule: the most frequent pattern of administration being 4-5 times daily ( $40 \%$ of recipients). Unfortunately, this study was not designed to evaluate the efficacy of procainamide and therefore provides no information on the relationship between the frequency of administration and therapeutic efficiency.

In view of its primary action as a cardiodepressant drug, ventricular dysrhythmias, bradycardia, hypotension and shock have been reported following its use (Goodman \& Gilman, 1975). In the present study $3.3 \%$ of recipients developed cardiovascular effects which were attributed to the drug, and of these almost half were judged to be of life-threatening severity, although no patient actually died as a result. Adverse reactions occurred more frequently with increasing daily doses of the drug and in patients with prolonged hospitalization. Reactions were also reported more frequently in females than males, although the reason for this was not apparent. The frequency of adverse effects was higher in patients with both acute myocardial infarction and congestive failure than in those with either condition singly or with neither, although the results did not attain conventional levels of statistical significance. This is presumably due to the severity of the underlying cardiac disease, although it has also been reported that absorption of this drug is reduced and metabolism and excretion impaired in patients with cardiac failure (Shaw, Kumana, Royds, Padgham \& Hamer, 1974; Biggar, 1975), and in the early phases after myocardial infarction (Koch-Weser, Klein, Foo-Canto, Kastor \& de Sanctis, 1969). 

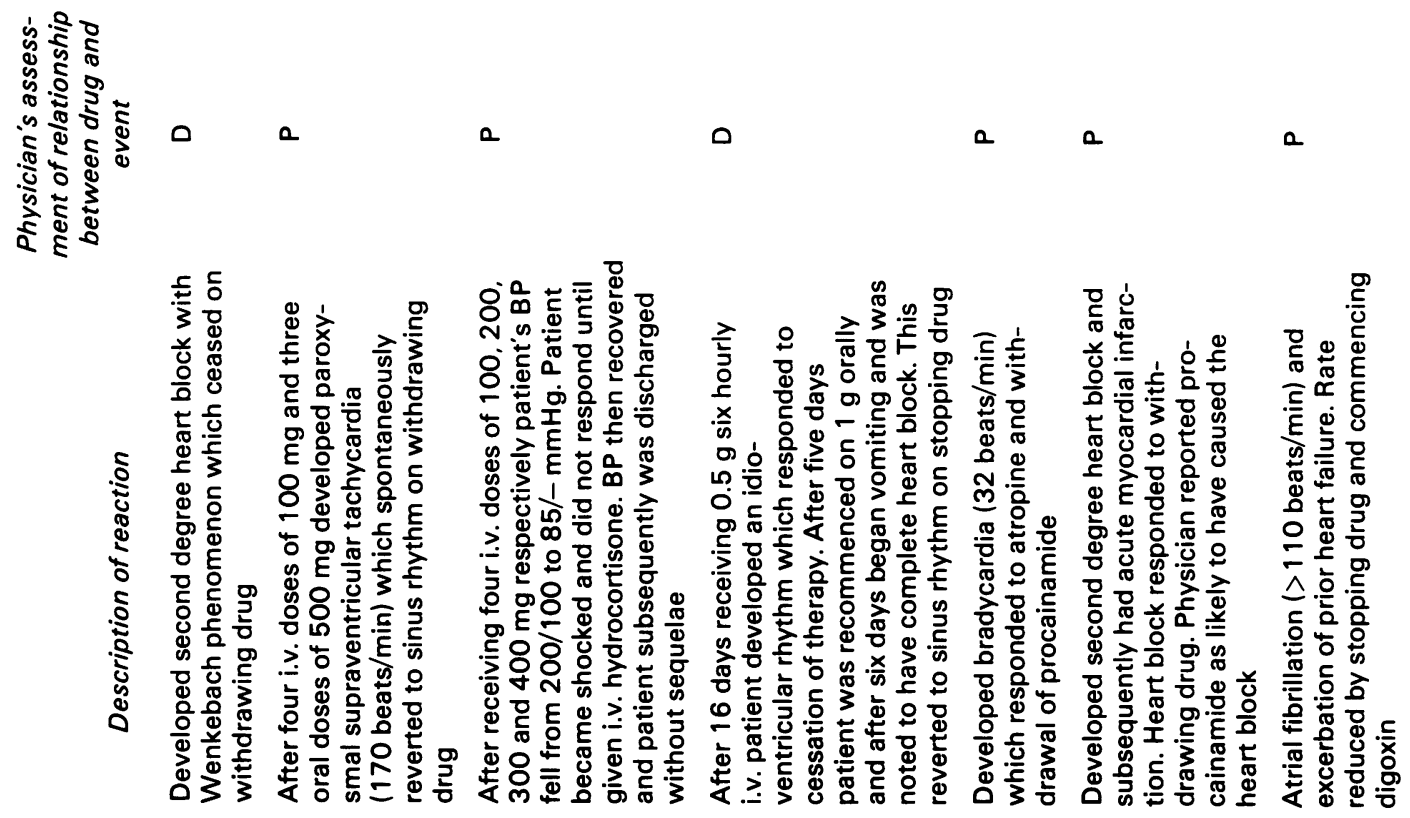

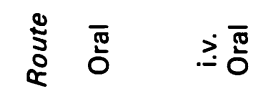

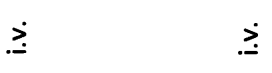

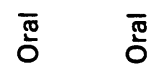

$\dot{E}$

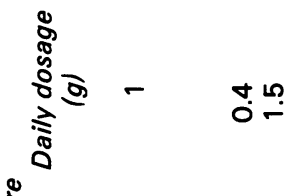

บ ปั้

ป็ำ

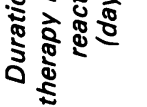
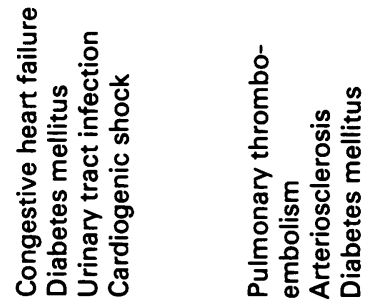

n $\infty$

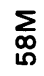

옷

岕
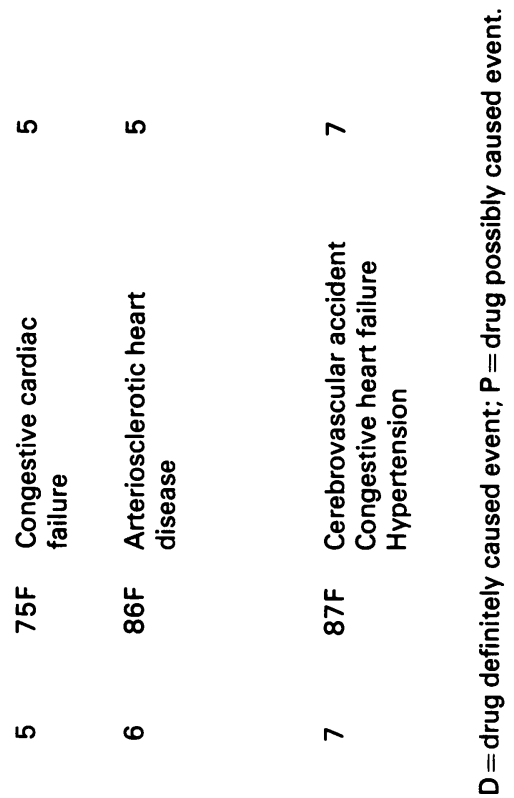

敎高

战

$\stackrel{4}{\infty}$

$\underset{\infty}{\stackrel{\omega}{\infty}}$

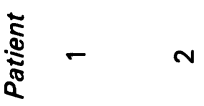

$m$

เ 
Procainamide is excreted partly by the kidney and partly by hepatic transformation to $\mathrm{N}$-acetylprocainamide. However, the drug is given only infrequently to patients with severe renal or hepatic impairment, and in the present study the adverse reactions were not related to presenting blood urea nitrogen or serum albumin concentrations.

Procainamide is known to be associated with drug fever and other allergic responses (de Warte, 1972). In this series eight patients (1.6\%) developed pyrexias which were not associated with demonstrable bacterial infections, and were attributed to the drug by the attending physicians. In all subjects the pyrexia settled upon cessation of the drug exposure. A further patient developed a significant eosinophilia (9\%) which was attributed to procainamide and was reported after 14 days of therapy with $1 \mathrm{~g}$ per day. Other serious sensitivity reactions such as agranulocytosis (Hickson, Davidson \& Walker, 1972) were not recorded in this group of patients.

One of the well-documented hazards of procainamide therapy is the development of systemic lupus erythematosis (Ladd, 1962; Blomgren, Condemi \& Vaughan, 1972; Kosowsky, Taylor, Lown \& Ritchie, 1973). This may present with polyarthralgia, myalgia, pleurisy or fever. None of the $\mathbf{4 8 8}$ patients in the present series were reported to have developed SLE or antinuclear factor antibodies during therapy. However, there were eleven patients in the total 29,524 participants who had clinically manifest SLE or highly positive antinuclear factor antibodies, and who had received procainamide as out-patients. All had been admitted as a result of this complication, and all had consumed procainamide regularly for periods exceeding 3 months.

One of the major recent advances in this area has been the discovery of the polymorphic nature of procainamide acetylation (Karlsson, Molin, Norlander \& Sjoqvist, 1974; Reidenberg, Drayer, Levy \& Warner, 1975) and its relation to toxicity, both shortterm cardiovascular effects (Campbell, Tilstone, Lawson, Hutton \& Lawrie, 1976), and induction of lupus erythematosis (Karlsson et al., 1974; Davies, Beedie \& Rawlins, 1975). Unfortunately, in the

Table 3 Factors influencing procainamide toxicity

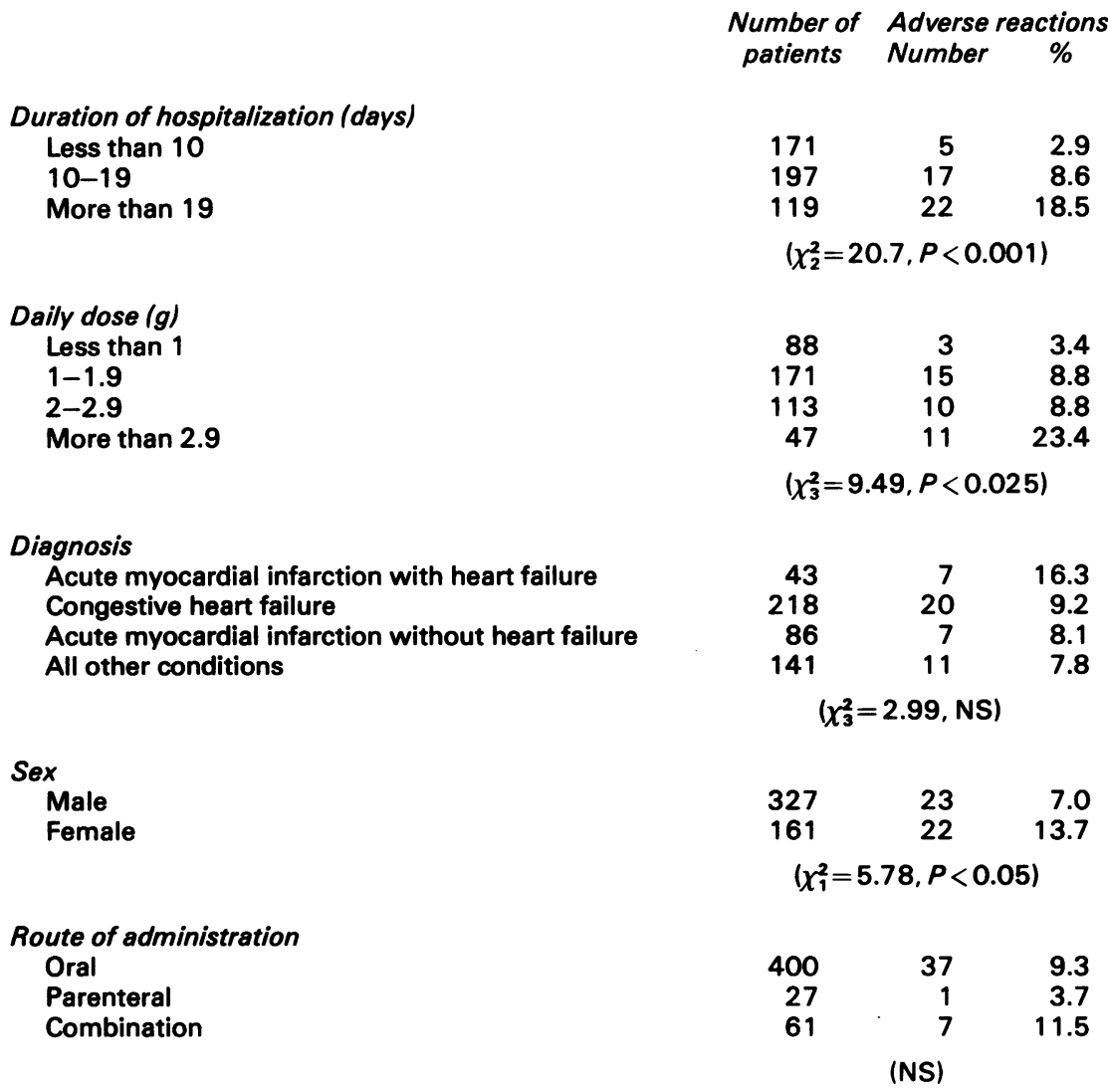


present study no information was available on patients' acetylator phenotype.

Campbell et al. (1976) reported that procainamide interferes with the use of sulphadimidine as a marker for acetylator capacity. These authors suggest that one explanation for their findings would be saturation of acetyltransferase enzyme during coincidental use of sulphonamides and procainamide. In order to test this hypothesis procainamide recipients in the present series were reviewed to determine the number who also received a sulphonamide during the same admission. There were only four such patients and hence this is a rare combination, and possible

\section{References}

BIGGAR, J.T. \& HEISSENBUTTEL, R.H. (1969). The use of procainamide and lidocaine in the treatment of cardiac arrhythmias. Progress in Cardiovascular Diseases, 6, 515-534.

BIGGAR, J.T. (1972). Arrhythmias and anti-arrhythmic drugs. Adv. int. Med., 18, 251.

BIGGAR, J.T. (1975). Pharmacological and clinical control of anti-arrhythmic drugs. Am. J. Med., 58, 479-483.

BLOMGREN, S.E., CONDEMI, J.J. \& VAUGHAN, J.H. (1972). Procainamide-induced lupus erythematosis. Am. J. Med., 52, 335-348.

CAMPBELL, W., TILSTONE, W.J., LAWSON, D.H., HUTTON, I. \& LAWRIE, T.D.V. (1976). Acetylator phenotype and the clinical pharmacology of slow-release procainamide. Br.J. clin. Pharmac., 3, 1023-1026.

DAVIES, D.M., BEEDIE, M.A. \& RAWLINS, M.D. (1975). Antinuclear antibodies during procainamide treatment and drug acetylation. Br. med. J., 3, 682-683.

de WARTE, R.O. (1972). Allergic diseases, diagnosis and management. Ed. Patterson, R., pp. 393-493. Philadelphia: Lippincott J.B. Co.

ELSON, J., STRONG, J.M., LEE, W.K. \& ATKINSON, A.J. (1975). Anti-arrhythmic potency of Nacetylprocainamide. Clin. Pharmac. Ther., 13, 366-371.

GOODMAN, L.S. \& GILMAN, A. (1975). The pharmacological basis of therapeutics. 5th Edition. New York: Macmillan \& Co.

HICKSON, B., DAVIDSON, R.J.L. \& WALKER, W. (1972). Agranulocytosis caused by procainamide. Scot. med. J., 17, 165-168.

JICK, H., MIETTINEN, O.S., SHAPIRO, S., LEWIS, G.P., SISKIND, V. \& SLONE, D. (1970). Comprehensive drug surveillance. J. Am. med. Ass., 213, 1455-1460.

KARLSSON, E., MOLIN, L., NORLANDER, B. \& SJOQVIST, interactions cannot be ruled out until prospective studies have been undertaken.

The Boston Collaborative Drug Surveillance Program is suported by Public Health Service Contract No. NIH-722010 from the National Institute of General Medical Sciences and in part from grants from the Veterans Administration, the Canadian Food and Drug Directorate, the Israeli Ministry of Health, the Scottish Home and Health Department, Auckland Hospital, New Zealand, Roger Williams General Hospital, Rhode Island and Hoffman-laRoche Inc.

Reprint requests to Dr H. Jick, Boston Collaborative Drug Surveillance Program, 400 Totten Pond Road, Waltham, Mass. 02154.

F. (1974). Acetylation of procainamide in man studied with a new gas chromatographic method. Br. J. clin. Pharmac., 1, 467-475.

KOCH-WESER, J. (1971). Pharmacokinetics of procainamide in man. Ann. N.Y. Acad. Sci., 179, 370-382.

KOCH-WESER, J. \& KLEIN, S.W. (1971). Procainamide dosage schedules, plasma concentrations and clinical effects. J. Am. med. Ass., 215, 1454-1460.

KOCH-WESER, J., KLEIN, S.W., FOO CANTO, L.L., KASTOR, J.A. \& de SANCTIS, R. (1969). Anti-arrhythmic prophylaxis with procainamide in acute myocardial infarction. New Engl. J. Med., 281, 1253-1260.

KOSOWSKY, B.D., TAYLOR, J., LOWN, B. \& RITCHIE, R.F. (1973). Long-term use of procainamide following acute myocardial infarction. Circulation, 47, 1204-1210.

LADD, A.T. (1962). Procainamide-induced lupus erythematosis. New Eng. J. Med., 267, 1957-1958.

MASON, D.T., SPANN, J.F., ZELIS, R. \& AMSTERDAM, E.A. (1970). Effects of anti-arrhythmic drugs on myocardial performance in man. Am. J. Cardiol., 25, 114-117.

REIDENBERG, M.M., DRAYER, D.E., LEVY, M. \& WARNER, H. (1975). Polymorphic acetylation of procainamide in man. Clin. Pharmac. Ther., 17, 722-730.

REYNELL, P.C. (1961). Prophylactic procainamide in myocardial infarction. Br. Heart J., 23, 421-424.

SHAW, T.R.O., KUMANA, C.R., ROYDS, R.B., PADGHAM, C.M. \& HAMER, J. (1974). Use of plasma levels in evaluation of procainamide dosage. Br. Heart J., 36, 265-270. 